ARTIGO

\title{
Sujeitos periféricos como metáfora da violência: reflexões a partir da música "O bagulho é doido", do rapper MV Bill
}

\author{
Peripheral subjects as a metaphor for violence: reflections based on the song " $O$ \\ bagulho é doido", by rapper MV Bill
}

\author{
Daniel Péricles ARRUDA* \\ https://orcid.org/o0oo-0002-8347-8215
}

\section{Introdução}

A partir do artigo Segurança e Racismo como Pilares Sustentadores do Estado Burguês, em que a autora, Andréa Pires Rocha (2020), expressa importantes contribuições a respeito dos pilares estruturais das relações étnico-raciais, das desigualdades e da criminalização, sinto-me tocado para compor e apresentar-lhes uma reflexão-irmã acerca dos sujeitos periféricos, tendo a arte como uma das principais fontes de saber e interação.

O Brasil é um dos países mais violentos do mundo. As violências que ocorrem no país são diversas, porém, afetam em maior proporção determinados sujeitos de maneira mais específica: jovens do sexo masculino negros, periféricos e pobres. É a juventude negra quem mais morre no país, seja por homicídio ou suicídio. Nesse aspecto, é preciso considerar também as mortes simbólicas que atuam contra o direito, a diversidade e a singularidade, são aquelas que eliminam ou tentam eliminar os desejos.

As periferias brasileiras têm bases históricas, são atravessadas por projetos e legislações de controle da terra, de estratégias arquitetônicas de exclusão, de ações políticas e ideológicas de segregação e por outras influências. Percebe-se que, em muitos contextos, as periferias são responsabilizadas pela violência social. Elas são vistas como a expressão do medo, do local perigoso. Elas recebem olhares contraditórios e também não deixam de ser territórios contraditórios. Por um lado, são muitas as periferias abandonadas pelo Estado; outras recebem recursos e serviços públicos insuficientes

\footnotetext{
* Arte-educador, rapper e poeta. Pós-doutor em Psicologia Social. Professor da graduação em Serviço Social, vinculado ao Departamento de Saúde, Educação e Sociedade e coordenador do Grupo de Estudos e Pesquisas sobre Vivências Artísticas, Culturais e Periféricas da Universidade Federal de São Paulo, campus Baixada Santista. (UFSP, Santos, Brasil). Edifício Central, R. Silva Jardim, 136, Vila Matias, Santos (SP), CEP: 11015-020. E-mail: pericles.daniel@unifesp.br.
}

(cc) Br $\mathrm{B}$ (s) Autora(s)/O(s) Autor(es). 2019 Acesso Aberto Esta obra está licenciada sob os termos da Licença Creative Commons Atribuição 4.0 Internacional (https://creativecommons.org/licenses/by/4.o/deed.pt_BR), que permite copiar e redistribuir o material em qualquer suporte ou formato, bem como adaptar, transformar e criar a partir deste material para qualquer fim, mesmo que comercial. O licenciante não pode revogar estes direitos desde que você respeite os termos da licença. 
e/ou precários, muitas sofrem com a presença estatal violenta. Por outro lado, temos vários movimentos comunitários de sociabilidade e resistência, o que não significa que o debate público acerca da desigualdade social já está resolvido ou que o Estado não deve se responsabilizar por aquilo que produz.

Esses territórios são ignorados por muitos moradores de regiões circunvizinhas, mas ao mesmo tempo há outras perspectivas: por exemplo, muitas periferias são visitadas por vários turistas, e os interesses são diversos: querem ver pessoalmente o que só viam por meio das redes sociais, fazer um turismo da constatação; querem desenvolver projetos sociais ou culturais; querem conhecer a experiência de transitar pelos becos e vielas, viver a experiência de estar ali; também devem estar à procura da selfie no alto do morro, da fotografia com o menino segurando o fuzil, da curtição nos bailes funk, da procura de outros prazeres.

O fato é que nenhuma periferia é igual a outra, mas, comumente, a violência, o preconceito, o estigma e o abandono têm sido alguns dos desafios, das questões vivenciadas por muitos sujeitos periféricos sobre os quais recai a imagem caricata do mal, do sujeito culpado de sua própria condição, do responsável pelas desigualdades, do representante da insegurança social. Recaem contra eles as ações públicas de segurança, até mesmo com nomes que dizem pacificar, porém, não é isso que se vê.

A partir dessas reflexões iniciais, este artigo pretende refletir sobre a condição dos sujeitos periféricos, com foco na adolescência e juventude, tendo como base a música do rapper MV Bill, "O bagulho é doido", faixa musical que compõe o CD lançado em 2006, intitulado Falcão: o bagulho é doido. Para isso, alguns versos da música são apresentados ao longo do texto, com o intuito de valorizar o seu potencial crítico, poético e político.

Alex Pereira Barbosa, mais conhecido como MV Bill, oriundo da Cidade de Deus (RJ), é um dos ícones da música rap no Brasil, obtendo reconhecimento pelo seu vasto trabalho artístico que aborda de maneira profunda e reflexiva a realidade de muitos adolescentes e jovens das periferias brasileiras. Além do CD, também produziu, em 2006, um documentário e um livro homônimos: Falcão: meninos do tráfico (ATHAYDE; MV BILL, 2006), em parceria com Celso Athayde. Essas três produções (CD, documentário e livro) reacenderam o debate no país acerca da condição da adolescência/juventude no tráfico de drogas ${ }^{1}$, das implicações sobre as armas de fogo e das relações étnico-raciais.

É importante dizer que, em continuação ao projeto apresentado em 2006, MV Bill e Celso Athayde perceberam que a realidade dos meninos entrevistados estava entrelaçada com outras realidades, formando o que os autores chamam de "teia". Um dos fios que formavam essa teia eram as mulheres. Por isso, em 2007, os autores lançaram o livro Falcão: mulheres e o tráfico (ATHAYDE; MV BILL, 2007), no qual

1 No artigo são apresentados os termos "tráfico de drogas", "drogas" e "traficante" a título de sua identificação usual em muitos contextos, mas não se desconsidera a crítica e outros entendimentos acerca desses significantes. 
apresentam o modo como essas mulheres, sujeitas periféricas, constroem suas vidas, suas relações e suas visões de mundo.

Assim, é importante considerar que os processos de produção das desigualdades, por serem elas estruturais, atravessam gerações, alimentam a ideia de que as pessoas são causadoras de sua própria pobreza, de que o mundo não se transforma, de que os sujeitos periféricos se tornam o que são porque não lutaram para vencer ou que não venceram porque não lutaram.

Resumidamente, o rap "O bagulho é doido" nos estimula a pensar que a questão não está na luta, mas sim na indiferença, conforme os sujeitos que estão em questão. Por isso, consideramos importante mergulhar nesse rap que apresenta elementos ainda existentes na atualidade, atentos às interlocuções e aos interlocutores presentes na composição.

\section{Escutando os sujeitos periféricos}

Sem corte, liga a filmadora e desliga o holofotel

Se quer me ouvir, permaneça no lugar/

(MV BILL)

"O bagulho é doido", título da música de MV Bill, é também uma expressão muito utilizada pelas juventudes periféricas, que significa uma situação complicada ou difícil. Porém, conforme o contexto, pode remeter a alguma experiência diferente ou surpreendente.

Percebe-se que o campo das linguagens periféricas é pleno de significantes a partir das experiências territoriais e afetivas de seus sujeitos. E a música segue esse caminho a partir dos versos iniciais apresentados anteriormente na epígrafe deste tópico.

Para mergulhar no sentido da música, apontamos que a mensagem inicial é "sem corte", ou seja, o objetivo do rap é mostrar a realidade como ela é, sem edições - como se diz: realidade nua e crua. Para isso, tem-se a permissão para gravar, ou seja, a autorização para escutar, sem a pretensão de sensacionalismo, isto é, sem "holofote". Lembramos que essa música foi apresentada em um contexto em que MV Bill estava realizando shows, palestras, entrevistando jovens e outros moradores de periferias e realizando atividades culturais pelo país, por isso a música apresenta um cenário de diálogo a partir do lugar e da condição em que o jovem se encontra.

Um fato importante é que a música apresenta várias simbologias e interpretações diferentes. MV Bill canta o rap como se fosse o próprio jovem envolvido no tráfico, um discurso na primeira pessoa que expressa a coletividade de muitos sujeitos. Em alguns trechos, em sintonia com a composição, aparecem narrativas dos jovens entrevistados por MV Bill, falas reais. Assim, como um pedido e uma condição, a partir do interesse do outro por saber a narrativa do jovem, na interpretação anuncia-se que, para ouvir, é preciso "permanecer no lugar". É preciso estar parado para que se dê atenção ao relato, vindo a partir de quem vive. 
Esse jovem tratado na música simboliza a experiência de muitos. E como ele se sente ao vivenciar processos de estigmatização? "Sou detrito que tira o sono do doutor/ Seria o Jason, se fosse um filme de terror" (MV BILL, 2006). Na verdade, não exatamente como se sente - mas como seria visto? Como um "detrito", porém, com potencialidade de causar incômodo, com força para afetar o outro, no caso o "doutor", que aqui não se sabe ao certo quem seria, mas pelo enredo da música, pelo uso da palavra na sociedade brasileira no tratamento de determinadas pessoas em razão de suas posições sociais e, principalmente, pela experiência desses jovens, nos faz pensar no promotor ou no juiz, figuras do Judiciário. E como são tratados os "detritos"? Por exemplo, é recente o caso de uma juíza do Paraná que condenou um homem negro a catorze anos de prisão por cometer furtos e por participar de organização criminosa. Na argumentação, a juíza escreveu em sua decisão que o suspeito é "seguramente integrante do grupo criminoso, em razão de sua raça”.

Já no campo cinematográfico, esse jovem equipara-se a Jason, protagonista/vilão da série de filmes de terror Sexta-feira 13 (CUNNINGHAM, 1980), personagem que causa pânico, que persegue e ataca suas vítimas, difícil de matar, e que quando morre, renasce e volta a perseguir, dando origem às várias continuações da franquia. É importante destacar que ele não surge por acaso: o primeiro filme da série, de 1980, conta a história de Jason, criança que morreu afogada no lago de um acampamento, sem ser socorrida por negligência dos monitores do local. Nessa primeira parte, a série de assassinatos é praticada pela mãe de Jason como forma de vingar a morte de seu filho. Nos outros filmes, Jason retorna e assume esse papel. Dentre várias razões, podemos considerar que as mortes causadas por ele estão associadas à vingança, mas também a um modo de expressar o seu sofrimento e ao desespero que sentiu ao morrer afogado. Antes do terror, há o suspense: o barulho na porta, o vulto, o silêncio, a luz que se apaga. Jason provoca insegurança e medo até mesmo antes de ser visto, e quando surge, suas vítimas se desesperam afogadas no medo.

Seja "detrito", seja "Jason", trata-se de construções negativas, temidas pela sociedade. Entretanto, na crítica poética, nos faz pensar que são construções que também contêm a imagem de quem os condena.

Assim são os processos de criminalização pelos quais muitos sujeitos periféricos acabam sendo acometidos, em um contexto em que jovens de classes média e alta, praticando as mesmas coisas que os jovens periféricos, não são tratados da mesma forma. Isto é:

\footnotetext{
Desembaça, saia na fumaça/ O bonde tá pesado e você tá achando graça/ Tipo peste, tá no sudeste, tá no nordeste, no centro-oeste/ Teu pai te dá dinheiro, você vem e investe/ No futuro da nação, compra pó na minha mão/ Depois me xinga na televisão/ Na sequência, vai pra passeata levantar cartaz/ Chorando e com as mãos sinalizando o símbolo da paz/. (MV BILL, 2006)
}

A questão das substâncias psicoativas identificadas como ilícitas articula-se nesse cenário em que se tem o "investimento"/“financiamento" daqueles que dizem lutar pela paz - daqueles que, na poética do rap, são gentis com o jovem que está na boca de fumo, na biqueira, na lojinha, mas longe dali o hostilizam. 
Cena semelhante aparece no filme Tropa de elite (o primeiro), em que jovens brancos de uma faculdade fazem parte de um projeto social desenvolvido em um morro no Rio de Janeiro, e um deles é o que compra drogas do traficante e repassa na faculdade. Em certo contexto do filme, esses jovens e outros fazem um protesto contra a violência, pois seus amigos foram assassinados no morro. E é isso, esses jovens participam do processo, mas se tornam imunes por uma série de combinações. Na estruturação do tráfico de drogas, eles têm mais facilidades de se blindar.

Sobre essa questão são relevantes as produções de Andréa Pires Rocha (2013; 2018) sobre a relação entre adolescentes e jovens com tráfico de drogas e suas implicações com o proibicionismo e a criminalização. A partir dessa ótica, Rocha (2013) indaga: “Quem são usuários? Quem são traficantes? É neste ponto que justificamos o porquê de todo este debate, pois a diferença no tratamento entre traficante e usuário abre brechas para a criminalização dos jovens pobres" (ROCHA, 2013, p. 574).

No contato direto com os sujeitos periféricos, MV Bill incorpora na música uma narrativa impactante de um dos jovens entrevistados: "Se eu morrer, nasce outro que nem eu ou pior, ou melhor/ Se eu morrer eu vou descansar/ Ah, sonhar, nessa vida não dá pra sonhar, não/ Amanhã, eu não sei nem se eu vou tá aí/". Lembram da reflexão anterior sobre o Jason?

Não tem medo da morte aquele que já está simbolicamente morto. A morte não mata a reprodução da condição em que muitos jovens se encontram. A morte, para o jovem apresentado no rap, não é algo temido, pois ela não existe, já aconteceu; caso aconteça, será uma segunda morte, mas, mesmo assim, é uma morte que não mata - essa é a trama. E se acontecer, em outro sentido, o que resta é descansar, pois numa vida sem sonhos ou repleta de conflitos não se tem certeza do futuro. Mas

Veja que ironia, que contradição/ O rico me odeia e financia minha munição/ Que faz faculdade, trabalha no escritório/ Me olha como se eu fosse um rato de laboratório/ Vem de Cherokee, vem de Kawasaki/ Deslumbrado com a favela como se tivesse vendo um parque de diversões/ Se junta com os vilões, se sente por um instante Ali cuzão e os quarenta ladrões/. (MV BILL, 2006)

MV Bill apresenta o encontro de realidades diferentes, a relação e indiferença entre a negação e afirmação. A periferia nesse contexto seria um território usual, rentável, encantado.

Porém, jovens pobres e ricos não são tratados da mesma maneira, pois se "me levam pra cadeia, me transformam em detento/ Você vai pra uma clínica tomar medicamento/" (MV BILL, 2006). O que essas relações produzem são mais mortes, violências: "A droga que cê usa é batizada com sangue/ É mais financiamento, mais armas, bangue-bangue/" (MV BILL, 2006). Essas são algumas características desse processo, por isso "o bagulho é doido", pois é complexo, irônico, contraditório. Em seguida, o refrão da música contribui para articularmos e compreendermos essas relações: 
Já vou ficar no lucro se passar de dezoito/ Depois que escurece o bagulho é doido/ O mesmo dinheiro que salva também mata, jovem com ódio na cara/ Terror, que fica na esquina esperando você chegar/ Se passar de dezoito, depois que escurece o bagulho é doido/ O mesmo dinheiro que salva também mata, jovem com ódio na cara/ Terror, que fica na esquina esperando você/. (MV BILL, 2006)

Durante a gravação do documentário - projeto iniciado em 1998 e finalizado em 2006 , dos dezessete jovens entrevistados por MV Bill, dezesseis morreram. Ocupar uma função no tráfico de drogas requer cuidado, fidelidade, atenção, mas, mesmo assim, não são garantias de que a vida não está em risco. Por isso, passar dos dezoito anos de idade representa o lucro, ou seja, "sobrevivi até aqui".

É interessante pensar o significante "escurecer", que pode remeter à noite, período que requer mais atenção do menino que vigia o território e deve ficar concentrado, como o falcão, ave que enxerga bem, voa rápido e realiza manobras com agilidade. Mas escurecer também se associa ao fechar dos olhos ou ao apagar da vida, à morte do corpo. Como é difícil a vida: "Quem sou eu? (eu não sei)/ Já morri, já matei/ Várias vezes eu rodei, tive chance e escapei/ E o que vem? Eu não sei/ Talvez, ninguém saiba/ Eu penso no amanhã e sinto muita raiva/" (MV BILL, 2006).

A raiva ao pensar no amanhã é sentida no presente. A raiva e o ódio não são sentimentos exclusivos desses jovens, fazem parte da constituição e expressão humana, porém, aqui há outro teor. No caso do rap, fazem pensar como os sujeitos agem a partir desses sentimentos e contra quem.

\footnotetext{
Pois o ódio, este fio solto de meu relato sobre a violência, tem de encontrar seu novelo e armar um laço com sentido: assim como a invisibilidade provavelmente esteve em sua origem, o tráfico lhe servirá de conduto e a cumplicidade policial lhe proverá o álibi hipócrita, garantindo-lhe sobrevida com proteção e provocação. (SOARES; MV BILL; ATHAYDE, 2005, p. 111)
}

Independentemente do que aconteça, esse jovem pode dizer: "Mesmo assim eu continuo sendo o foco da história". (MV BILL, 2006). Poderíamos dizer que essa é a dialética do menino-falcão: "Você sabe o que isso representa/ Seu vício é que me mata/ Seu vício me sustenta” (MV BILL, 2006).

Ao término da música, MV Bill apresenta algumas narrativas dos jovens, em um momento em que eles falam de si, de seus sentimentos, do que pensam sobre suas condições. Dentre essas narrativas, os jovens contam: "Vida na favela é maluco, às vezes dá vontade de se matar/ Às vezes dá vontade de sumir/ Às vezes eu fico se perguntando por causa de que eu entrei na boca/ [...] Realidade da vida que o bagulho é doido/ Realidade da favela que o bagulho é doido/".

\section{Considerações finais}

O rap de MV Bill é uma aula. Toca diretamente no sujeito da ferida. Narra abertamente as tensões e as contradições vivenciadas por jovens periféricos. Por meio de sua arte e 
de sua identificação, MV Bill conseguiu ouvi-los e transformar o trabalho dessa escuta em uma arte política e sensível.

O que se percebe é que a atualidade da música de MV Bill chama a atenção para a cultura da violência no país e como a segurança pública tem seus alvos, ou seja, está voltada para determinadas pessoas e não para as estruturas sociais que fomentam e retroalimentam os extermínios e outras modalidades de violências, consequentemente produzindo e potencializando a ideia - e até mesmo a certeza, ou seja, uma falsa certeza - de que sujeitos periféricos são metáforas da violência.

As drogas, as armas e as munições não nascem nas periferias: como a $\mathrm{AK} 47$ (fuzil) e a cocaína, antes de chegarem lá, elas foram produzidas, reproduzidas, transportadas, fornecidas, há toda uma logística. Nesse percurso participam pessoas de vários grupos institucionais e de vários campos do saber, político e científico. Mas a culpa é atribuída ao sujeito periférico, em especial, ao menino marcado pelo seu modo de vestir, pela tatuagem, pelo traço feito na sobrancelha, pela música que escuta, como o rap e o funk. Logo, esse menino-falcão é apreendido, mas não conseguem apreender todo o sistema que está em volta dele. O tráfico e o tráfego, no atacado e no varejo, nos chamam a atenção para fugir da simplificação que simboliza esses sujeitos periféricos como um câncer social. Em poucas palavras, parafraseando o rap de MV Bill: "O bagulho ainda continua doido".

\section{Referências}

ATHAYDE, Celso; MV Bill. Falcão: mulheres e o tráfico. Rio de Janeiro: Objetiva, 2007.

ATHAYDE, Celso; MV Bill. Falcão: meninos do tráfico. Rio de Janeiro: Objetiva, 2006.

CUNNINGHAM, Sean Sexton (Dir.). Sexta-feira 13 - Parte I (Filme). Los Angeles, Burbank (Califórnia, EUA): Paramount Picture; Warner Bros., 1980.

MV BILL. O bagulho é doido (Faixa 2). Falcão: o bagulho é doido (CD). São Paulo: Universal Music, 2006.

PADILHA, José (Dir.). Tropa de elite (Filme). Rio de Janeiro: Zazen, Posto 9, Feijão Filmes, Universal Pictures do Brasil, 2007.

ROCHA, Andréa Pires. Segurança e racismo como pilares sustentadores do Estado Burguês. Argumentum, Vitória, v. 12, n. 3, p. 10-25, set./dez. 2020. Disponível em: https://periodicos.ufes.br/argumentum/article/view/32628/22387.

ROCHA, Andréa Pires. Prisão provisória de jovens pelo crime de tráfico de drogas após a realização das audiências de custódia em Londrina (PR). 2018. Relatório (Pós-doutorado em Serviço Social) - Escola de Serviço Social, Universidade Federal do Rio de Janeiro, Rio de Janeiro, 2018. 
ROCHA, Andréa Pires. Proibicionismo e a criminalização de adolescentes pobres por tráfico de drogas. Serv. Soc. Soc., São Paulo, n. 115, p. 561-58o, jul./set. 2013.

SOARES, Luiz Eduardo; MV BILL; ATHAYDE, Celso. Cabeça de porco. Rio de Janeiro: Objetiva, 2005.

\section{Daniel Péricles ARRUDA}

Arte-educador, rapper e poeta. Professor da graduação em Serviço Social, vinculado ao Departamento de Saúde, Educação e Sociedade e coordenador do Grupo de Estudos e Pesquisas sobre Vivências Artísticas, Culturais e Periféricas da Universidade Federal de São Paulo, campus Baixada Santista. É graduado em Serviço Social pela PUC Minas, mestre (bolsista do Ford Foundation International Fellowships Program, turma 2010) e doutor em Serviço Social pela PUC-SP, pós-doutor em Psicologia Social pela PUC-SP, em formação em psicanálise pelo Instituto Langage, e aluno do $2^{\circ}$ ano do curso Clínica Psicanalítica: Conflito e Sintoma, do Instituto Sedes Sapientiae. 